\title{
Neuroimaging resilience to trauma: convergent evidence and challenges for future research
}

\author{
A. Norbury ${ }^{1} \quad$ | M. M. Perez-Rodriguez ${ }^{1} \quad \mid \quad$ A. Feder ${ }^{1}$
}

${ }^{1}$ Department of Psychiatry, Icahn School of Medicine at Mount

Sinai, New York, NY, USA

\section{Correspondence}

Agnes Norbury PhD, Department of Psychiatry, Icahn School of Medicine at Mount Sinai, New York, NY, USA

Email: agnes.norbury@mssm.edu

Funding information

CDC-NIOSH U01 to MPR and AF, grant number

1U01OH011473-01
Resilience, or the phenomenon of successful adaptation following significant trauma exposure, is a complex, multidimensional, and dynamic process. To date, research on neural mechanisms involved in human resilience has comprised of two major research streams - involving individuals with childhood and adulthood trauma exposure, respectively. Although there are systematic differences in how both trauma and resilience have been defined across these two bodies of research, some striking regions of convergence emerge when considering the literature as a whole. Here, we review functional imaging studies from across these two research streams, alongside discussion of some of the methodological difficulties involved in quantifying both trauma and resilience in human participants. Due to the broad scope of this literature, we restrict the scope of our narrative to several key domains where studies from across these two bodies of work implicate common neural circuitry. These areas of convergence include brain networks implicated in emotion regulation, responses to rewards, cognitive control and cognitive flexibility, and social cognition. Further, we briefly review functional imaging evidence related to proposed mechanisms underlying resilient outcomes: namely active coping, cognitive reappraisal and successful fear extinction. Finally, we also touch upon several ongoing issues in neuroimaging study design that will need to be addressed in order to enable us to harness insight from such studies to improve treatments for - or, ideally, guard against the development of - debilitating post-traumatic stress syndromes. 


\section{1 | INTRODUCTION}

\section{1 | Defining resilience: a complex and dynamic process}

Remarkably, only a subset of people go on to experience sustained psychological problems following experience of a traumatic event. Epidemiological estimates for clinically-significant post-traumatic stress symptoms range from $5-22 \%$ for adults exposed to natural disasters, life-threatening injuries, or physical assault. These estimates rise to $46-65 \%$ for individuals who experience sexual violence - although rates vary significantly according to social background, country of residence, and other demographic features (Shalev et al., 2017; Bromet et al., 2018; Watson, 2019). Similarly, whilst experience of childhood trauma (particularly physical, sexual, or emotional abuse) is a robust predictor of poorer future mental health, roughly $10-25 \%$ of individuals with a history of such maltreatment go on to function better than expected across behavioural, emotional, and educational domains (Walsh et al., 2010).

In the field of psychiatry, the phenomenon of better than expected psychosocial functioning following exposure to significant trauma or stress is known as resilience. Recently, a consortium of researchers involved in the study of stress-related disorders have proposed that resilience can best be defined as "an outcome of good mental health following an adverse life event or a period of adversity" (Kalisch et al., 2017). This represents a deliberately operational and atheoretical approach to defining resilience that is agnostic as to the mechanisms underlying this outcome. Importantly, from this perspective, resilience is not simply the inverse of vulnerability or risk for psychiatric disease, but rather describes a status it is only possible to confer after the fact of a traumatic event (Yehuda and Flory, 2007).

Importantly, the expected level of psychosocial functioning for a given individual should take into account their lifetime trauma burden (Karam et al., 2014; Feder et al., 2016). Various researchers have therefore proposed that resilience can best be quantified by regressing metrics of psychosocial functioning against an appropriate measure of trauma exposure severity: such that positive residuals from this model represent better than expected ('resilient') outcomes, and negative residuals represent worse than expected ('vulnerable') outcomes - compared to what would be predicted based on the group as a whole (Amstadter et al., 2014, 2016; van Harmelen et al., 2017; loannidis et al., 2020). Resilience-promoting factors can then be described as any resource (biological, psychological, social or socioeconomic) that decreases the risk of poor outcomes following adverse circumstances. Resilience-promoting factors may include both protective factors that help buffer the impact of stress, and resources that are able to foster positive compensatory changes following trauma exposure (Luthar et al., 2006; Schultze-Lutter et al., 2016). Indeed, much empirical research on resilience-promoting factors has emphasised that resilience is a dynamic process, involving active adaptation and engagement of compensatory mechanisms in response to adversity (Feder et al., 2009; Rutter, 2012; Kalisch et al., 2017; Scheffer et al., 2018; loannidis et al., 2020). Critically, resilience-promoting factors are not independently additive, but interact in complex ways (Luthar et al., 2006; Fritz et al., 2018a; Liebenberg, 2020). It is therefore vital not to study such factors in isolation, but rather in the context of each other - ideally within the same individuals.

The necessity of considering multiple interacting factors, detailed lifetime trauma history, and how symptoms change over time (all ideally within the same participants) presents a considerable challenge to the experimental study of human resilience. However, we remain hopeful that the increasing availability of remote, minimally intrusive datagathering tools, in conjunction with modern analytic techniques for complex time-series data, hail the prospect of making considerable progress in resilience research: explicitly by embracing such complexity (Scheffer et al., 2018; Kalisch et al., 2019). 


\subsection{Studies of human resilience: two major research streams}

Research on factors that influence resilience to trauma can be described in terms of two major research streams: the first involving the study of children, adolescents, and adults who have history of childhood maltreatment (usually defined as physical, sexual, or emotional abuse or neglect), and the second examining the effects of adulthood trauma exposure (often in professionally-determined at-risk populations such as emergency service workers and military personnel, but also in individuals with experience of major disasters, traumatic accidents, or exposure to interpersonal and/or sexual violence).

Research on factors that influence resilience to trauma can be described in terms of two major research streams: the first involving the study of children, adolescents, and adults who have history of childhood maltreatment (usually defined as physical, sexual, or emotional abuse or neglect), and the second examining the effects of adulthood trauma exposure. This division can be explained by the different conceptual and experimental considerations involved in studying these cohorts. For example, the developmental stage (age or pubertal status) of individuals at onset may be critical in studies of childhood trauma, but less so in adulthood (Harpur et al., 2015; Dunn et al., 2019; Gee, 2020). Similarly, the temporal nature (chronicity) of trauma exposure may be an important differentiating factor between childhood neglect or abuse, and some more punctate adulthood traumas, such as being involved in an accident or disaster (see Box 1: Quantifying trauma). In consequence, there are some systematic differences in how both trauma and resilience have been defined and quantified in experimental studies of childhood maltreatment and adulthood trauma-exposure (see Box 2: Quantifying resilience).

Nevertheless, when considering the literature from these two bodies of work in parallel, there are some striking regions of convergence. By highlighting these regions, we hope to shed light on some of the general mechanisms underlying adaptive outcomes after trauma. We fully acknowledge that such an approach inevitably results in the masking of important complexities, such as those touched on above. For a fuller discussion, we direct the reader towards excellent recent reviews encompassing the developmental complexities involved in the study of childhood maltreatment (loannidis et al., 2020; Moreno-López et al., 2020; Méndez Leal and Silvers, 2021).

\subsection{What value can neuroimaging bring to the understanding of resilience?}

The ultimate aim of resilience research is to harness insight into protective and compensatory mechanisms to improve treatments for - or, ideally, prevent the development of - posttraumatic stress symptoms (Kalisch et al., 2017). If we accept that the brain is the final effector in the pathway from environment to psychological experience, it should be possible to locate the effects of even distal resilience-related factors here. Given appropriate power and sensitivity, neuroimaging is therefore a tool that may enhance our understanding of the mechanisms associated with different routes to resilient outcomes in humans. However, it is also important to be clear about the scope of inferences we can draw from the current data. Most existing studies have yet to incorporate the important nuances described above in particular, investigating multiple potential resilience-promoting factors within the same individuals, and including multiple measurements in the same individuals over time (although see below for important exceptions). If these issues can be addressed, neuroimaging studies may progress our understanding of differential responses to trauma by generating psychopathology-informed hypotheses for further testing in animal models, developing tools to better phenotype currently diagnosed patients or at-risk individuals, and perhaps even enabling the development of directly imaging-informed interventions: such as targeted neurofeedback, brain stimulation, or cognitive-emotional training. 


\section{Box 1. Quantifying trauma}

Assessing the severity of different traumatic experiences is not a trivial task. Indeed, to a large extent, the degree to which any event is traumatic is determined by the psychological impact on the person or people involved (Green, 1990). However, such a definition poses some difficultly for studies of resilience, which aim to investigate individual differences in response to similarly adverse events.

Events sufficient to fulfil criteria for a diagnosis of post-traumatic stress disorder (PTSD) have been codified within the American Psychiatric Association's Diagnostic and Statistical Manual (DSM) as 'Category A' events - specifically, in DSM-5, as being "exposed to death, threatened death, actual or threatened serious injury, or actual or threatened sexual violence" (American Psychiatric Association, 2013). In the World Health Organization's International Classification of Diseases (ICD-10), the requirement is simply that a person has experienced an event or situation "of exceptionally threatening or catastrophic nature, which would be likely to cause pervasive distress in almost anyone" (World Health Organization, 1993). Under either scheme, presence of such an event in an individual's history is usually probed using a structured clinical interview (e.g., Weathers et al., 2013). Experience of childhood trauma in younger research participants may be assessed using developmentally sensitive interviews with a child's primary caregiver (e.g., Goodyer et al., 2010).

In comparison, in studies involving adult participants, experience of childhood trauma is often assessed using retrospective questionnaires, such as the Childhood Trauma Questionnaire (Bernstein et al., 1994). Notably, a recent meta-analysis reported poor agreement between prospective and retrospective measures of childhood maltreatment (Baldwin et al., 2019). Although both prospective and retrospective measures identify groups of at-risk individuals, they appear to highlight largely non-overlapping sets of people - meaning that it may not be valid to assume the same risk mechanisms apply to individuals identified using different methods.

Further, although both intensity and chronicity are considered to be important dimensions of trauma, it is not always clear how to combine these different aspects of adverse event exposure in a standardized way. Some studies have addressed this issue by restricting recruitment to individuals exposed to a specific precipitating event, for example in volunteers from the World Trade Center rescue and recovery worker cohort (Pietrzak et al., 2014a), or individuals with combat trauma (Keane et al., 1989). However, even in such samples, there is likely to be additional lifetime trauma exposure in many participants. One approach to this problem is to use a data reduction technique such as principal components analysis (PCA) to combine several different continuous measures into a single index of trauma exposure severity (e.g., to combine different aspects of childhood family experience; van Harmelen et al., 2017. It important to bear in mind when synthesizing data in this way that there may also be trauma-specific considerations to take into account during analysis - for example when considering responses to differently gendered angry faces in people exposed to intimate partner violence (Fonzo et al., 2010). 


\section{Box 2. Quantifying resilience}

In trauma-exposed populations. In neurobiological studies with adult participants, resilience has often been defined on the basis of the absence of a DSM Axis-1 disorder diagnosis following significant trauma exposure. Such categorical analyses may be complemented by dimensional approaches that relate measures to current severity scores for PTSD, depression, or anxiety symptoms. However, it is increasingly acknowledged that symptom sum scores for specific diagnoses are not the only key outcome variable in studies of resilience. Indeed, trauma-related psychopathology is highly heterogenous, and different symptom dimensions may differentially relate to overall burden of disability (e.g., Pietrzak et al., 2014b) - suggesting more nuanced approaches may be warranted. Conversely, studies of the effects of childhood maltreatment have tended to take a more holistic approach towards assessing resilience, including a greater focus on psychosocial outcomes, and examining functioning across multiple domains (McGloin and Widom, 2001; Cicchetti and Rogosch, 2012). Recent examples of this approach across the literature include examining resilience across different functional outcome categories in children (Burt et al., 2016), analysing disruption to work, social, and family life in addition to PTSD symptomatology in trauma-exposed adults (Horn et al., 2016), and the use of PCAderived cross-domain psychosocial functioning scores in an adolescent cohort (van Harmelen et al., 2017).

Importantly, the notion of good functioning invoked by definitions of resilience is environment-dependent: adaptive behaviour in violent, volatile, or resource-poor environments may not conform to normative accounts of behaviour in more stable or resource-rich environments (Luthar et al., 2006). Further, psychosocial environments may differ across individuals within a shared wider context - e.g. for individuals who identify as different genders and/or belong to different racial or ethnic groups (Tolin and Foa, 2008; Portnoy et al., 2018; Street and Dardis, 2018; Brondolo, 2015). For example, differences in resilience between men and women have been found to be explained by differences in trauma type exposure across genders (particularly sexual violence; Tolin and Foa, 2008; Portnoy et al., 2018), and socialized gender norms may further contribute to differences in chronic environmental stress exposure and propensity to engage in less adaptive coping strategies (Street and Dardis, 2018). In particular, racism is an additional source of trauma in minoritized people that may be under-recognized by current clinical assessments (Carter, 2007; Williams et al., 2018).

In the general population.. Contrary to the operational definition of resilience described here (Kalisch et al., 2017), some researchers have also examined population variation in self-reported trait resilience. For example, the ConnorDavidson Resilience Scale (CD-RISC) probes how likely individuals are to endorse statements such as "I am able to adapt to change" and "I tend to bounce back after illness or hardship" (Connor and Davidson, 2003). There is somewhat equivocal evidence regarding the relationship between trait resilience and outcomes following trauma exposure (Daniels et al., 2012; Powers et al., 2014). Interestingly, a recent study of emergency department attendees found that a negative association between CD-RISC score close to admission and PTSD symptoms six months in the future was mediated by lower social withdrawal in higher trait resilience individuals - suggesting that the impacts of trait resilience on functional outcome may be via increased ability to maintain or recruit social support (Thompson et al., 2018). Further, most questionnaire measures of resilience relate to a specific conceptualisation of resilience that focuses on individual 'grit' or 'hardiness' and that may not translate well to non-Western cultural settings - particularly those that emphasise the role of communities rather than individuals in fostering resilience (Meili and Maercker, 2019; Mendenhall and Kim, 2019). An alternative approaches for studies of resilience in the general population is to study the mechanisms underlying resilience on the basis of experimental intervention data - for example as reflected in lower self-reported fear or physiological reactivity during stress induction paradigms. 


\section{2 | FUNCTIONAL IMAGING OF RESILIENCE: AREAS OF CONVERGENCE}

Here, we review functional neuroimaging studies of resilience in humans from across the childhood and adulthood trauma exposure literatures. We build on previous work reviewing neural mechanisms implicated in resilience to stress across the lifespan (van der Werff et al., 2013), and functional imaging studies of adults and adolescents resilient to childhood maltreatment (Moreno-López et al., 2020; Méndez Leal and Silvers, 2021). As in these works, we focus on studies that included trauma-exposed asymptomatic ('resilient'), trauma-exposed symptomatic ('vulnerable'), and non-trauma exposed healthy participants - allowing investigators to tease apart effects of trauma exposure and current symptom experience on neural activity. In order to advance on previous scholarship, we also primarily discuss literature published since 2013. Due to the relatively recent emergence of larger cohort studies, and progress in anaIytic and reporting standards across the field of neuroimaging, this has the advantage of allowing us to devote greater weight to better powered work (see Discussion). Where possible, we follow discussion of cross-sectional study designs with evidence from longitudinal and interventional studies, which provide insight into direction of effects and causal relationships to outcomes, respectively.

In order to highlight regions of convergence, our discussion is informed by thematic concentrations of previous resilience research: with the bulk of results restricted to areas of significant overlap between the childhood and adulthood trauma exposure literature. Specifically, we describe findings relating resilient outcomes to brain circuits subserving emotion regulation, responses to rewards, cognitive control and cognitive flexibility, and social support and social cognition. Further, we briefly review relevant evidence from studies of potential mechanisms underlying resilient outcomes - namely active coping, cognitive reappraisal and fear extinction. Of note, the brain regions highlighted across these domains broadly correspond to those described in recent models of psychological vulnerability to trauma, full details of which are beyond the scope of the current manuscript, but which can be found elsewhere (Pitman et al., 2012; Patel et al., 2012; Yehuda et al., 2015).

\subsection{Emotion regulation}

Imaging studies have consistently identified several core brain regions as showing increased activity during human emotional responses: including the medial prefrontal and cingulate cortex, ventral striatum, amygdala, and hippocampus (Dalgleish, 2004). Poor outcomes following trauma have been associated with hyper-responsivity to traumarelated and unrelated emotional stimuli in individuals with both child and adulthood trauma exposure, in particular with decreased down-regulation of the amygdala by the medial prefrontal cortex (mPFC) during emotional provocation (Patel et al., 2012; Whittle et al., 2013). Conversely, convergent evidence suggests that resilient individuals exhibit increased ability to downregulate neural responses to stress or threat, via medial prefrontal inhibition of responses in a network of emotionally-responsive brain regions, including the amygdala and anterior cingulate cortex.

Specifically, early studies across several imaging modalities identified increased activity in in the mPFC (including rostral anterior cingulate regions), and decreased activity in emotion-responsive regions such as the dorsal anterior cingulate and amygdala, in resilient compared to symptomatic trauma-exposed adults (van der Werff et al., 2013). These differences were identified both at rest, and during tasks designed to actively engage emotion-regulation mechanisms (challenge with unpleasant images, sounds, or trauma scripts). A recent review of individuals with a history of childhood maltreatment found evidence for increased frontolimbic connectivity during emotion-processing tasks in resilient compared to healthy adults (Moreno-López et al., 2020), including greater down-regulation of amygdala activity during negative emotion regulation in healthy children with a history of childhood maltreatment (Schweizer et al., 2016). In a study of adult typhoon survivors, Granger causality analysis of task-free intrinsic connectivity data re- 
vealed increased inhibition of the amygdala by the mPFC in individuals without PTSD compared to both symptomatic survivors and non trauma-exposed controls - suggesting that increased resting inhibition of the amygdala by medial prefrontal regions may reflect a resilience-promoting adaptation following trauma (Chen et al., 2018).

These cross-sectional findings are bolstered by evidence from several recent longitudinal studies. In a study of children who had experienced institutional care prior to adoption, it was found that children who showed reduced amygdala responses to images of their parents (compared to strangers) showed greater reductions in self-reported anxiety three years later (Callaghan et al., 2019). A further study in this population showed that previously institutionalized youth with stronger ventromedial prefrontal-hippocampal connectivity estimates during an aversive learning task that robustly activated the amygdala also had reduced anxiety scores at two-year follow-up (Silvers et al., 2016). In the adult literature, lower amygdala reactivity to fearful faces, measured a few weeks post-trauma in individuals recruited from a hospital emergency department, was associated with lower self-reported PTSD symptoms one year later (Stevens et al., 2017). Importantly, a recent prospective investigation showed that in a large sample of trainee police officers, greater pre-exposure anterior prefrontal activity during an emotional action control task (requiring approach of angry faces and avoidance of happy ones) both predicted lower levels of PTSD symptoms at post-exposure follow-up, and moderated a positive relationship between previous trauma load and symptom increase during training (Kaldewaij et al., 2021). In this study, increases in amygdala activation were found to be an acquired effect of trauma exposure, rather than a prospective marker of vulnerability for PTSD. Together, these studies provide evidence that improved prefrontal regulation of midbrain responses to social threat cues near to the time of trauma may predict resilience to post-traumatic stress and anxiety symptoms - possibly via recruitment of additional hippocampal circuitry. From an interventional perspective, a pilot trial of $\mathrm{fMRI}$-guided real-time neurofeedback in combat veterans demonstrated evidence of decreased amygdala signal and increased amygdala-vmPFC connectivity following training, but found that effectiveness in reducing PTSD symptoms was not superior to a sham condition (Zotev et al., 2018). A larger trial in individuals recruited from a pre-deployment military program found that training to volitionally downregulate EEG-derived amygdala signal was successful in decreasing amygdala BOLD signal and increasing amygdala-mPFC functional connectivity, as measured via follow-up fMRI. Although active training resulted improved emotional regulation performance in terms of response times on an emotional Stroop task and scores on an alexithymia questionnaire, it had no effect on self-reported anxiety symptoms (Keynan et al., 2019). This represents a promising step towards development of a feasible and scalable neurally-guided intervention for individuals at risk of significant trauma exposure - however it is yet to be demonstrated whether this approach will be effective in mitigating development of psychological symptoms following real-world trauma.

\section{2 | Reward responsivity}

Both adults with a history of childhood maltreatment and adults with a diagnosis of PTSD have been demonstrated to exhibit blunted neural responses to rewards - particularly in response to social reward cues (Dillon et al., 2009; Hanson et al., 2015, 2016; Sailer et al., 2008; Elman et al., 2009; Nawijn et al., 2015). Comparatively preserved ventral striatal reward responses during reward receipt and anticipation have, on the other hand, been identified in resilient individuals.

In a cross-sectional study, greater ventral striatal responses to happy faces were observed in Category A traumaexposed individuals who did not meet criteria for PTSD, compared to those with PTSD (Felmingham et al., 2014). A later analysis of $N=820$ university students drawn from the Duke Neurogenetics Study cohort found that increased ventral striatal BOLD during reward anticipation/receipt during a card guessing game significantly weakened the relationship between childhood trauma exposure and adult anhedonia symptoms - including when controlling for other 
depression symptoms and recent life stress (Corral-Frías et al., 2015). A further study carried out in the aftermath of the 2016 US presidential election found that amongst individuals who felt negatively affected by the outcome (who also belonged to historically marginalized groups in terms of ethnicity and/or sexual orientation), higher nucleus accumbens BOLD signal and higher mPFC-accumbens connectivity during reward receipt attenuated the relationship between election-related distress and depression symptoms (Tashjian and Galván, 2018).

In a longitudinal assessment of combat-exposed paramedics, decreased responses to rewards in the nucleus accumbens post-, but not pre-exposure, were found to be related to self-reported PTSD symptoms - suggesting that preserved reward responses may be a marker of resilience to PTSD, rather than prospective predictor (Admon et al., 2013). In contrast, in a recent study of a community-based sample of adolescents (a substantial proportion of whom had a history of severe childhood maltreatment including physical and/or sexual abuse), greater pallidal BOLD in response to positive images was cross-sectionally associated with lower depression symptoms, and higher putamen BOLD was associated with lower increases in depression scores at 2 year follow-up (Dennison et al., 2016). Greater reactivity to rewarding social/environmental cues may therefore also represent a resilience-promoting factor against the development of depression symptoms.

\section{3 | Cognitive flexibility and cognitive control}

Deficits in cognitive function, including working memory, attention, and cognitive flexibility, have been observed in adults with a history of childhood maltreatment and individuals with a diagnosis of PTSD - which are not fully accounted for by comorbid depression, substance use disorders, or history of traumatic brain injury (Gould et al., 2012; Scott et al., 2015). Conversely, greater cognitive flexibility, as measured using a behavioural attention-switching task 1-2 weeks following traumatic injury, has been shown to predict lower PTSD symptoms one month later (BenZion et al., 2018). Differences in function in prefrontal and hippocampal regions during performance of tasks that require attentional control and cognitive flexibility have also been identified in resilient individuals (although NB there is evidence that the relationship between current PTSD symptom severity and cognitive function may be bidirectional; Jacob et al., 2019).

An early study found that both resilient and non trauma-exposed healthy control groups showed significantly greater BOLD in the ventrolateral, medial, and dorsolateral PFC during an inhibitory control task, compared to individuals with PTSD (Falconer et al., 2008). Similarly, Blair and colleagues found evidence for greater BOLD signal in the dorsolateral PFC and superior frontal gyrus during incongruent Stroop trials in a healthy trauma-exposed group, compared to both individuals with PTSD and trauma-free controls (Blair et al., 2013). In a notable recent study, Mary and colleagues demonstrated that resilient and trauma-unexposed, but not vulnerable, adults exhibited significant decoupling between prefrontal regions and subcortical structures during a conscious suppression of an experimentallygenerated intrusive memory (Mary et al., 2020). Further analysis revealed that top-down modulation of subcortical memory structures (hippocampus, parahippocampal gyrus, and precuneus) by prefrontal regions was associated with successful intrusive memory suppression, but that this effect was absent in the PTSD group (who showed a reversed pattern of information flow). Together, these studies suggest that preserved function in prefrontal-subcortical cognitive control networks may be necessary for resilience to development of clinical levels of PTSD symptoms.

Interestingly, in a recent analysis of longitudinal data from 120 university students that probed multiple domains of function within the same individuals, higher amygdala response to threat and lower ventral striatum activity to reward predicted future increases in anxiety in students with average or low but not high prefrontal activity during a working memory task (Scult et al., 2019). This suggests that preserved prefrontal executive control may 'rescue' risk for anxiety in these individuals. Further, a longitudinal assessment of trauma-exposed adults found that increased 
hippocampal BOLD signal during inhibitory control task measured 1-2 months post-trauma predicted decreased PTSD symptom severity at 3 and 6 month follow-up in both an initial discovery and replication sample (van Rooij et al., 2018). As the hippocampus has been identified as a crucial structure involved in linking cognition, memory and mood (Speer and Delgado, 2017), it is likely to have high relevance for resilience to post-traumatic stress syndromes, that are characterised by alterations in mood, cognitive function, and intrusive thoughts and memories.

Finally, Silveira and colleagues recently used task-free imaging data from the NCANDA cohort ( $N=392)$ to show that an association between childhood trauma severity and executive function difficulties was mediated by lower functional connectivity between a network of hub regions implicated in cognitive/behavioural control and sensorimotor integration (specifically, the postcentral and precentral gyri, dorsal anterior cingulate cortex, intraparietal sulcus, and anterior insula cortex). Preserved interconnectivity between these frontal regions (particularly the postcentral gyrus and dorsal anterior cingulate) was related to lower reported executive dysfunction at baseline, and predicted lower likelihood of high-risk drinking behaviour at 1-4 year follow-up (Silveira et al., 2020). This suggests that in addition to protecting against post-traumatic stress symptoms, preserved prefrontal function may be an important path towards resilience to maladaptive coping behaviours that may also emerge following trauma, such as substance abuse.

\subsection{Social support and social cognition}

Behavioural and epidemiologic studies have identified social support as a vital factor in promoting resilience to both childhood and adulthood trauma (van Harmelen et al., 2016, 2017; Fritz et al., 2018b; Yule et al., 2019). Social discrimination has been demonstrated to impact function in emotion-responsive neural circuitry including the amygdala, insula, and anterior cingulate cortex, even in the absence of (or after controlling for) associated psychological symptoms (Akdeniz et al., 2014; Clark et al., 2018). Conversely, a recent review describing the protective effects of social support on brain responses to social stress and aversive events (electric shock or heat pain) concluded that the effect of supportive social environments may converge with other resilience-promoting traits in positively modulating function in the perigenual anterior cingulate and other prefrontal cortical regions (Holz et al., 2020). One further study found evidence that greater maternal support attenuated the relationship between childhood adversity and neural responses to fearful emotional faces in the anterior cingulate cortex, insula, nucleus accumbens, and frontal pole (Wymbs et al., 2020). Importantly, higher levels of social cognitive function (ability to infer the thoughts of others and navigate the social world) may help foster adaptive outcomes following trauma, by conferring the ability to recruit and maintain these important social support structures (Stevens and Jovanovic, 2019; Lepore and Kliewer, 2019). However, to date, very few studies have examined role of neural activity related to social cognition in resilience following trauma exposure.

In a cross-sectional study of young adults with a history of emotional maltreatment, no evidence was found for differences in neural responses to social exclusion between a group of healthy individuals (with low to moderate history of maltreatment) and those with a diagnosis of a DSM Axis-1 disorder (who had moderate to high maltreatment scores) (van Harmelen et al., 2014). There was also no evidence of a relationship between resilience to childhood adversity (defined as the absence of any recent DSM Axis-1 disorder diagnosis following significant family discord) and neural responses to social rejection in a longitudinal study of adolescents (Fritz et al., 2019) - although the authors report that this null finding may be related to the relatively low frequency of abuse and high socioeconomic status of individuals in the study sample. Further research is therefore needed on the proximal neural mechanisms underlying the role of social support and high social cognitive functioning in resilience. In general, greater consideration of individuals' broader social environments is likely to be critical to improving our understanding of mechanisms underlying resilient outcomes (see Box 2; Biglan et al., 2012). 


\subsection{Studies of potential resilience mechanisms}

Active Coping Greater tendency to engage active or problem-focused coping strategies in the face of stress (endorsement of statements such as "I take additional actions to get rid of the problem" or "I concentrate my effort on doing something about it") has been associated with lower levels of PTSD symptoms in cross-sectional assessments in the aftermath of trauma (e.g., Stratta et al., 2015; Bistricky et al., 2019; Getnet et al., 2019). Further, there is preliminary evidence that switches towards endorsing active coping strategies accompany response to cognitive-behavioural therapy for PTSD (Bourdon et al., 2019). Experimental studies of individual differences in coping styles have implicated variation in medial prefrontal function in adaptive responses to prolonged (versus acute) stressors. For example, a study in a small group of healthy men found that individuals with high levels of early life stress but low trait rumination scores decreased amygdala and increased vmPFC perfusion during performance of a mental arithmetic stress task, whereas men with early life stress but high trait rumination showed the opposite effect (Wang et al., 2013). A further study of healthy volunteers during an acute stress paradigm (involving exposure to highly aversive images) found that whilst the ventromedial PFC exhibited significant deactivation during early task runs of the task, degree of recovery of function (BOLD signal increase) later in the task was both positively related to self-reported active coping and negatively related to frequency of engagement in maladaptive coping behaviours (Sinha et al., 2016).

This finding is consistent with observations from the preclinical literature that whilst it may be adaptive to downregulate prefrontal function (resulting in upregulated function in emotion-responsive brain regions) during acute stress, this response should be modified as the stressor becomes prolonged (Maier and Watkins, 2010; Sinha et al., 2016). However, it should be noted that temporal effects measured during a single laboratory study session represent a very different timescale to naturalistic prolonged human stress - which is more likely to be measured in years than minutes. Further, the directionality of the relationship between mPFC recovery during chronic stress and coping style is currently not clear - i.e., whether increased prefrontal capacity to regulate emotional responses may result in increased likelihood of self-identifying as an 'active coper', or vice versa. Differential reinforcement of active versus avoidant coping strategies may also relate to traditional gender roles and other social norms (McLean and Anderson, 2009; Street and Dardis, 2018; Box 2) - therefore interrelationships between these factors may warrant careful attention in future investigations of coping behaviours.

Cognitive re-appraisal The ability to re-evaluate the meaning of experiences has been suggested to play an important role in adaptive responses to trauma, as well forming a core part of many psychological therapies for affective disorders (Hofmann et al., 2013). Cognitive reappraisal has been described as an 'effortful emotion regulation strategy' that individuals may employ in order to buffer risk for adverse outcomes following trauma exposure (Rodman et al., 2019). In a recent ecological momentary assessment study carried out in currently-remitted individuals with a history of depression, individual differences in positive appraisal (ability to "focus on positive meaning") were found to be mutually reinforcing of self-reported feelings of resilience and associated with lower occurrence of residual depressive symptoms (Hoorelbeke et al., 2019). From an imaging perspective, meta-analyses have highlighted the involvement of ventrolateral and dorsolateral prefrontal cortices, the dorsal ACC, and the amygdala in effortful emotional regulation in heathy individuals - with differences in function in these regions identified between healthy control groups and patient samples (Zilverstand et al., 2017).

There is mixed evidence for an association between neural function during laboratory tests of cognitive reappraisal (which instruct participants to try and consciously modulate their emotional response to affective images) and psychological symptoms in trauma-exposed individuals. A study in small group of adolescent girls exposed to violent assault found that participants who responded better to trauma-focused cognitive-behavioural therapy demonstrated 
decreased functional connectivity between the amygdala and mid-posterior insula cortex during re-appraisal of negative images following treatment (Cisler et al., 2016). However, regional BOLD signals measured during performance of a cognitive reappraisal task in larger sample of adults with PTSD was not found to be associated with clinical response to exposure-based psychotherapy (Fonzo et al., 2017). Finally, a longitudinal study found a relationship between prefrontal recruitment during effortful cognitive reappraisal (and associated downregulation of amygdala reactivity during perception of negative stimuli) and subsequent risk for depression - but not anxiety - symptoms in maltreated youth (Rodman et al., 2019). Together, these data suggest that individual differences in ability to successfully engage this kind of active emotion regulation strategy may help buffer against the deleterious effects of trauma exposure on mood, but are not necessarily related to changes in anxiety and post-traumatic stress symptom levels.

Successful fear extinction Successful updating of fear memories is likely to be a prerequisite for adaptive functioning when transitioning from dangerous to safe contexts (Lissek and van Meurs, 2015). The ventromedial prefrontal cortex (VmPFC) has been identified as a core brain structure for the successful maintenance of fear extinction learning in both human and animal studies (Phelps et al., 2004; Schiller and Delgado, 2010). Specifically, greater retention of extinction learning during recall testing has been associated with greater BOLD signal in the VMPFC and hippocampus (Milad et al., 2007; Fullana et al., 2018). A recent study demonstrated that enhancement of lab-based extinction learning (via inclusion of a novel neutral outcome in place of the omitted aversive stimulus) was associated with representation of surprise-related learning signals in the vmPFC and a distinct pattern of vmPFC-amygdala connectivity (Dunsmoor et al., 2019). This implies that this circuitry might be critical to attempts to augment extinction learning in a clinical context (Fullana et al., 2020). Indeed, greater success of a psychological therapy aimed at promoting extinction learning (prolonged exposure therapy) has been linked to a variety of baseline brain responses during emotion-related tasks - including higher vmPFC signal during emotional regulation, greater magnitude of prefrontal responses during viewing of fearful faces, and greater inhibition of the amygdala by lateral PFC transcranial magnetic stimulation (Fonzo et al., 2017). Further, vmPFC activity has been demonstrated to be central to the success of imagined fear extinction, which may be particularly relevant to the psychotherapeutic context (Reddan et al., 2018). Together, these studies suggest that ability to recruit prefrontal structures during emotional experience may be important to the success of exposure-based treatment strategies - and likely may play a role in successful maintenance of extinction learning more generally.

\section{3 | DISCUSSION}

Here, we summarised functional imaging studies of resilience to both childhood and adult-aged trauma. We identified three major areas of convergence across the literature: implicating networks of brain regions involved in emotion regulation, responses to rewards, and cognitive control in better outcomes following trauma. Although taking a highlevel approach necessarily involved omission of many interesting complexities, we believe that such an overview may be useful in highlighting commonalities across the field. Further, we attempt to draw attention to parallels between findings from studies in trauma-exposed individuals, and findings from studies of proposed resilience mechanisms (both lab-based and as activated by treatments for post-traumatic stress). This may be particularly important for identifying resilience mechanisms that are amenable to augmentation in high-risk populations or already vulnerable trauma-exposed individuals.

We found robust evidence for a role of preserved medial prefrontal function, in particular in downregulation of limbic responses to emotional stimuli, in fostering resilience outcomes. This is consistent with evidence from animal 
and human experimental stress-induction paradigms, which have reliably implicated the re-emergence of mPFC activity levels with adaptive coping as stress exposure becomes prolonged (Maier and Watkins, 2010). Intriguingly, it has recently been shown that chronic social defeat stress-susceptible mice (who show impairments in social interaction) exhibit selective reductions in ventromedial prefrontal spike frequencies - suggesting a potential role of preserved vmPFC function in mediating adaptive social behaviour following chronic stress (Abe et al., 2019). This finding is in line with emerging experimental evidence from human studies, that implicate perigenual and prefrontal function in mediating positive effects of social support on responses to stress and pain (Holz et al., 2020). Despite a clear role in fostering positive outcomes following trauma exposure (Stevens and Jovanovic, 2019), there is currently very little literature on the neural correlates of social functioning and social cognitive ability in resilient humans.

There is also convergent evidence for an association between preserved reward signal processing in the ventral striatum and resilience to anhedonia and depression symptoms. One possibility is that preserved reward system function fosters resilient outcomes by allowing individuals to continue to engage in rewarding experiences (including socially-derived rewards), buffering the impacts of stress by diminishing control of attention and behaviour by negative stimuli. It is also possible that intact reward circuitry plays an important role in anticipation of future positive experiences - for example a hippocampal-midbrain-vmPFC circuit has recently been implicated in imagination of future positive outcomes in humans (ligaya et al., 2019).

Finally, there is increasing acknowledgement of the role of brain regions implicated in executive function and cognitive control in predicting positive outcomes following trauma, specifically networks including frontal and dorsolateral cortex, and the hippocampus. The hippocampus has been identified as an important region for the interplay between memory and mood: adult hippocampal neurogenesis has been shown to play an important role in cognitive flexibility, which may enable individuals to disengage from trauma-related memories and cognition, decreasing distress from cardinal PTSD symptoms such as intrusive thoughts and reminder-prompted flashbacks (Aupperle et al., 2012; Anacker and Hen, 2017). A notable recent study demonstrated the importance of connectivity between prefrontal and subcortical (including hippocampal) regions in cognitive control in terms of supressing unwanted memory retrieval: with intact function in this network apparent in resilient but not vulnerable traumatised individuals (Mary et al., 2020). Although this signature may not be specific to PTSD, it may represent an important vulnerability factor for the development of post-traumatic stress and other maladaptive coping mechanisms (e.g., substance use problems) following trauma (Ersche, 2020). Recent work in this area has also highlighted the importance of considering how multiple resilience-relevant factors may interact within the same individuals - specifically, how higher levels of prefrontally-mediated executive function may 'rescue' risk for anxiety in individuals with high neural responses to threat and low responses to rewards (Scult et al., 2019).

For understandable reasons, much of the work discussed here is unable to speak to the raft of complexities identified as being important in understanding resilience. The majority of the studies to date are both retrospective and cross-sectional in design, and few (particularly in the adult literature) have tested the same participants at multiple timepoints. This is significant, as only longitudinal studies can really tease out whether differences observed in resilient individuals represent pre-existing traits or active adaptations in the face of trauma. There are also some methodological weaknesses in some of the studies reviewed here. Much of the extant literature is based on small sample sizes, which are likely to be underpowered (Szucs and loannidis, 2020), and many older studies have also made use of overly-liberal multiple comparison correction methods, which may be subject to inflated type 1 error rates (Eklund et al., 2016; Cox et al., 2017). However, larger cohort-based functional imaging studies of resilience are starting to emerge, and some key findings have now been replicated in well-powered samples (e.g., Corral-Frías et al., 2015; Silveira et al., 2020). Finally, the identification of robust neuroimaging biomarkers (e.g., for prognosis in populations at high risk of trauma exposure) will likely require greater attention to the within-subject reliability of 
these measures - particularly given recent observations that this reliability may be low for both mean regional BOLD signal during emotional response/regulation tasks and canonical resting state networks (Nord et al., 2017; Elliott et al., 2019, 2020). Multivariate approaches that exploit the high dimensionality of imaging data - perhaps in conjunction with naturalistic stimulus sets - may be more appropriate for this purpose (Dubois and Adolphs, 2016; Finn et al., 2020).

Despite these challenges, interventions derived from neuroscientific studies of resilience are starting to be implemented in real-world settings (Greenberg, 2006; Waugh and Koster, 2015; Keynan et al., 2019). A complementary research stream examining the neural correlates of treatment response to existing therapies may give further insight into neural resilience mechanisms that may be 'activated' by successful engagement with treatment (e.g., increased ability to assimilate or reappraise trauma memories following psychotherapy). Together, it is hoped that these approaches may help resilience researchers achieve the aim of improving preventative and remediative interventions for stress-related disorders.

\section{Acknowledgements}

This work was supported by a CDC-NIOSH U01 Award to MPR and AF, Grant Number 1U01OH011473-01.

\section{Conflict of Interest}

AF is named co-inventor on a patent application in the US, and several issued patents outside the US filed by the Icahn School of Medicine at Mount Sinai related to the use of ketamine for the treatment of PTSD. This intellectual property has not been licensed. AN and MPR have no relevant conflicts of interest to declare.

\section{Box 3: Recommendations for future studies}

- Studying multiple potential resilience-promoting factors within the same individual is necessary in order to tease apart how putative neurobiological resilience factors interact both with each other and with other sociodemographic factors known to affect resilience to trauma-related psychopathology. In particular, we would encourage greater consideration of an individual's social, cultural, and socioeconomic environment in future studies of neural mechanisms related to resilience.

- The trade-off for high power in large cohort studies is often the selective pressure on study measures (for inclusion, brevity, and ease of administration). However, accurate assessment of both resilience and the sociodemographic factors described above requires in-depth clinical phenotyping and trauma history screening, often by clinical interview with appropriately trained study personnel. In order to build our understanding of the neural correlates of resilience, future work should aim to hit a sweet spot in this trade-off between appropriate power and depth of individual phenotyping.

- An important next step will be to integrate neuroimaging metrics related to resilience with other biological measurements relevant to both individual differences in neural function and environmental exposure. Novel analytic approaches such as the calculation of polygenic risk scores, or quantification of gene co-expression modules may yield sufficient power in (single site) achievable imaging sample sizes to link neural correlates of psychological constructs to underlying biology (Dima and Breen, 2015; Bogdan et al., 2017). Greater integration of neuroimaging data into such pathways should improve our ability to interpret existing findings in terms of underlying molecular mechanisms. 


\section{References}

Abe, R., Okada, S., Nakayama, R., Ikegaya, Y. and Sasaki, T. (2019) Social defeat stress causes selective attenuation of neuronal activity in the ventromedial prefrontal cortex. Scientific Reports, 9, 9447. URL: https: //www . nature.com/articles/s41598019-45833-5.

Admon, R., Lubin, G., Rosenblatt, J. D., Stern, O., Kahn, I., Assaf, M. and Hendler, T. (2013) Imbalanced Neural Responsivity to Risk and Reward Indicates Stress Vulnerability in Humans. Cerebral Cortex, 23, 28-35. URL: https ://academic. oup. com/ cercor/article/23/1/28/327799.

Akdeniz, C., Tost, H., Streit, F., Haddad, L., Wüst, S., Schäfer, A., Schneider, M., Rietschel, M., Kirsch, P. and Meyer-Lindenberg, A. (2014) Neuroimaging Evidence for a Role of Neural Social Stress Processing in Ethnic Minority-Associated Environmental Risk. JAMA Psychiatry, 71, 672-680. URL: https://jamanetwork.com/journals/jamapsychiatry/fullarticle/ 1860850. Publisher: American Medical Association.

American Psychiatric Association (2013) Diagnostic and Statistical Manual of Mental Disorders. Washington, DC and London, England: American Psychiatric Association, fifth edition edn. URL: https://psychiatryonline.org/doi/book/10.1176/ appi. books. 9780890425596.

Amstadter, A. B., Maes, H. H., Sheerin, C. M., Myers, J. M. and Kendler, K. S. (2016) The relationship between genetic and environmental influences on resilience and on common internalizing and externalizing psychiatric disorders. Social Psychiatry and Psychiatric Epidemiology, 51, 669-678.

Amstadter, A. B., Myers, J. M. and Kendler, K. S. (2014) Psychiatric resilience: longitudinal twin study. The British Journal of Psychiatry: The Journal of Mental Science, 205, 275-280.

Anacker, C. and Hen, R. (2017) Adult hippocampal neurogenesis and cognitive flexibility - linking memory and mood. Nature Reviews Neuroscience, 18, 335-346. URL: https://www.nature.com/articles/nrn. 2017.45.

Aupperle, R. L., Melrose, A. J., Stein, M. B. and Paulus, M. P. (2012) Executive function and PTSD: Disengaging from trauma. Neuropharmacology, 62, 686-694. URL: http://www.sciencedirect.com/science/article/pii/s0028390811000785.

Baldwin, J. R., Reuben, A., Newbury, J. B. and Danese, A. (2019) Agreement Between Prospective and Retrospective Measures of Childhood Maltreatment: A Systematic Review and Meta-analysis. JAMA Psychiatry, 76, 584. URL: http://archpsyc. jamanetwork. com/article.aspx?doi=10.1001/jamapsychiatry.2019.0097.

Ben-Zion, Z., Fine, N. B., Keynan, N. J., Admon, R., Green, N., Halevi, M., Fonzo, G. A., Achituv, M., Merin, O., Sharon, H., Halpern, P., Liberzon, I., Etkin, A., Hendler, T. and Shalev, A. Y. (2018) Cognitive Flexibility Predicts PTSD Symptoms: Observational and Interventional Studies. Frontiers in Psychiatry, 9, 477. WOS:000446343200001.

Bernstein, D. P., Fink, L., Handelsman, L., Foote, J., Lovejoy, M., Wenzel, K., Sapareto, E. and Ruggiero, J. (1994) Initial reliability and validity of a new retrospective measure of child abuse and neglect. The American journal of psychiatry, 151, 1132-1136. URL: http://europepmc.org/abstract/med/8037246.

Biglan, A., Flay, B. R., Embry, D. D. and Sandler, I. N. (2012) The Critical Role of Nurturing Environments for Promoting Human Wellbeing. The American psychologist, 67, 257-271. URL: https://www.ncbi.nlm.nih.gov/pmc/articles/PMC3621015/.

Bistricky, S. L., Long, L. J., Lai, B. S., Gallagher, M. W., Kanenberg, H., Elkins, S. R., Harper, K. L. and Short, M. B. (2019) Surviving the storm: Avoidant coping, helping behavior, resilience and affective symptoms around a major hurricane-flood. Journal of Affective Disorders, 257, 297-306. URL: http: //www. sciencedirect.com/science/article/pii/s0165032718324066.

Blair, K. S., Vythilingam, M., Crowe, S. L., McCaffrey, D. E., Ng, P., Wu, C. C., Scaramozza, M., Mondillo, K., Pine, D. S., Charney, D. S. and Blair, R. J. R. (2013) Cognitive control of attention is differentially affected in trauma-exposed individuals with and without post-traumatic stress disorder. Psychological Medicine, 43, 8595. URL: https://www.cambridge.org/core/journals/psychological-medicine/article/cognitive-control-ofattention-is-differentially-affected-in-traumaexposed-individuals-with-and-without-posttraumatic-stressdisorder/EE326B3C8A6D9A577D9D8FF31603BBDD. 
Bogdan, R., Salmeron, B. J., Carey, C. E., Agrawal, A., Calhoun, V. D., Garavan, H., Hariri, A. R., Heinz, A., Hill, M. N., Holmes, A., Kalin, N. H. and Goldman, D. (2017) Imaging Genetics and Genomics in Psychiatry: A Critical Review of Progress and Potential. Biological Psychiatry, 82, 165-175. URL: http://www.sciencedirect.com/science/article/pii/s0006322317300343.

Bourdon, D.-, El-Baalbaki, G., Girard, D., Lapointe-Blackburn, and Guay, S. (2019) Schemas and coping strategies in cognitivebehavioral therapy for PTSD: A systematic review. European Journal of Trauma \& Dissociation, 3, 33-47. URL: http: //www.sciencedirect.com/science/article/pii/s2468749918300334.

Bromet, E. J., Karam, E. G., Koenen, K. C. and Stein, D. J. (2018) Trauma and Posttraumatic Stress Disorder: Global Perspectives from the WHO World Mental Health Surveys. Cambridge University Press. Google-Books-ID: GLZiDwAAQBAJ.

Brondolo, E. (2015) Racial and Ethnic Disparities in Health: Examining the Contexts That Shape Resilience and Risk. Psychosomatic Medicine, 77, 2-5. URL: http: //content . whealth. com/linkback/openurl? sid=WKPTLP : landingpage\&an=00006842201501000-00002.

Burt, K. B., Whelan, R., Conrod, P. J., Banaschewski, T., Barker, G. J., Bokde, A. L., Bromberg, U., Büchel, C., Fauth-Bühler, M., Flor, H., Galinowski, A., Gallinat, J., Gowland, P., Heinz, A., Ittermann, B., Mann, K., Nees, F., Papadopoulos-Orfanos, D., Paus, T., Pausova, Z., Poustka, L., Rietschel, M., Robbins, T. W., Smolka, M. N., Ströhle, A., Schumann, G. and Garavan, H. (2016) Structural brain correlates of adolescent resilience. Journal of child psychology and psychiatry, and allied disciplines, 57, 1287-1296. URL: http://europepmc.org/abstract/med/27079174.

Callaghan, B. L., Gee, D. G., Gabard-Durnam, L., Telzer, E. H., Humphreys, K. L., Goff, B., Shapiro, M., Flannery, J., Lumian, D. S., Fareri, D. S., Caldera, C. and Tottenham, N. (2019) Decreased Amygdala Reactivity to Parent Cues Protects Against Anxiety Following Early Adversity: An Examination Across 3 Years. Biological Psychiatry: Cognitive Neuroscience and Neuroimaging, 4, 664-671. URL: https://www.sciencedirect.com/science/article/pii/s2451902219300485.

Carter, R. T. (2007) Racism and Psychological and Emotional Injury: Recognizing and Assessing Race-Based Traumatic Stress. The Counseling Psychologist, 35, 13-105. URL: https://doi.org/10.1177/0011000006292033. Publisher: SAGE Publications Inc.

Chen, F., Ke, J., Qi, R., Xu, Q., Zhong, Y., Liu, T., Li, J., Zhang, L. and Lu, G. (2018) Increased Inhibition of the Amygdala by the mPFC may Reflect a Resilience Factor in Post-traumatic Stress Disorder: A Resting-State fMRI Granger Causality Analysis. Frontiers in Psychiatry, 9, 516. URL: https://www.ncbi.nlm.nih.gov/pmc/articles/PMC6204490/.

Cicchetti, D. and Rogosch, F. A. (2012) Gene Environment interaction and resilience: effects of child maltreatment and serotonin, corticotropin releasing hormone, dopamine, and oxytocin genes. Development and Psychopathology, 24, $411-427$.

Cisler, J. M., Sigel, B. A., Steele, J. S., Smitherman, S., Vanderzee, K., Pemberton, J., Kramer, T. L. and Kilts, C. D. (2016) Changes in functional connectivity of the amygdala during cognitive reappraisal predict symptom reduction during trauma-focused cognitive-behavioral therapy among adolescent girls with post-traumatic stress disorder. Psychological Medicine, 46, 3013-3023. URL: https://www.cambridge.org/core/journals/psychological-medicine/article/changesin-functional-connectivity-of-the-amygdala-during-cognitive-reappraisal-predict-symptom-reductionduring-traumafocused-cognitivebehavioral-therapy-among-adolescent-girls-with-posttraumatic-stressdisorder/8A4E4F3C65E7A7386D3F8A9DC5FE8012. Publisher: Cambridge University Press.

Clark, U. S., Miller, E. R. and Hegde, R. R. (2018) Experiences of Discrimination Are Associated With Greater Resting Amygdala Activity and Functional Connectivity. Biological Psychiatry: Cognitive Neuroscience and Neuroimaging, 3, 367-378. URL: http://www.sciencedirect.com/science/article/pii/s2451902217302100.

Connor, K. M. and Davidson, J. R. T. (2003) Development of a new resilience scale: The Connor-Davidson Resilience Scale (CD-RISC). Depression and Anxiety, 18, 76-82. URL: https://onlinelibrary.wiley.com/doi/abs/10.1002/da.10113.

Corral-Frías, N. S., Nikolova, Y. S., Michalski, L. J., Baranger, D. A., Hariri, A. R. and Bogdan, R. (2015) Stress-related anhedonia is associated with ventral striatum reactivity to reward and transdiagnostic psychiatric symptomatology. Psychological medicine, 45, 2605-2617. URL: https://www.ncbi.nlm.nih.gov/pmc/articles/PMC4700837/. 
Cox, R. W., Chen, G., Glen, D. R., Reynolds, R. C. and Taylor, P. A. (2017) FMRI Clustering in AFNI: False-Positive Rates Redux. Brain Connectivity, 7, 152-171. URL: https://www.liebertpub.com/doi/10.1089/brain.2016.0475.

Dalgleish, T. (2004) The emotional brain. Nature Reviews Neuroscience, 5, 583-589. URL: https : //www . nature .com/articles/ nrn1432. Number: 7 Publisher: Nature Publishing Group.

Daniels, J. K., Hegadoren, K. M., Coupland, N. J., Rowe, B. H., Densmore, M., Neufeld, R. W. J. and Lanius, R. A. (2012) Neural correlates and predictive power of trait resilience in an acutely traumatized sample: A pilot investigation. The Journal of Clinical Psychiatry, 73, 327-332.

Dennison, M. J., Sheridan, M. A., Busso, D. S., Jenness, J. L., Peverill, M., Rosen, M. L. and McLaughlin, K. A. (2016) Neurobehavioral markers of resilience to depression amongst adolescents exposed to child abuse. Journal of abnormal psychology, 125, 1201-1212. URL: https://www.ncbi.nlm.nih.gov/pmc/articles/PMC5119749/.

Dillon, D. G., Holmes, A. J., Birk, J. L., Brooks, N., Lyons-Ruth, K. and Pizzagalli, D. A. (2009) Childhood Adversity Is Associated with Left Basal Ganglia Dysfunction During Reward Anticipation in Adulthood. Biological Psychiatry, 66, 206-213. URL: http://www.sciencedirect.com/science/article/pii/s0006322309002327.

Dima, D. and Breen, G. (2015) Polygenic risk scores in imaging genetics: Usefulness and applications. Journal of Psychopharmacology, 29, 867-871. URL: https://doi .org/10.1177/0269881115584470.

Dubois, J. and Adolphs, R. (2016) Building a Science of Individual Differences from fMRI. Trends in Cognitive Sciences, 20, 425-443. URL: http://www.sciencedirect.com/science/article/pii/s1364661316300079.

Dunn, E. C., Soare, T. W., Zhu, Y., Simpkin, A. J., Suderman, M. J., Klengel, T., Smith, A. D. A. C., Ressler, K. J. and Relton, C. L. (2019) Sensitive Periods for the Effect of Childhood Adversity on DNA Methylation: Results From a Prospective, Longitudinal Study. Biological Psychiatry, 85, 838-849. URL: https://www.biologicalpsychiatryjournal.com/article/ S0006-3223(19)30038-1/abstract.

Dunsmoor, J. E., Kroes, M. C. W., Li, J., Daw, N. D., Simpson, H. B. and Phelps, E. A. (2019) Role of Human Ventromedial Prefrontal Cortex in Learning and Recall of Enhanced Extinction. Journal of Neuroscience, 39, 3264-3276. URL: https: //www. jneurosci.org/content/39/17/3264. Publisher: Society for Neuroscience Section: Research Articles.

Eklund, A., Nichols, T. E. and Knutsson, H. (2016) Cluster failure: Why fMRI inferences for spatial extent have inflated falsepositive rates. Proceedings of the National Academy of Sciences, 201602413. URL: https ://www . pnas . org/content/early/ 2016/06/27/1602413113.

Elliott, M. L., Knodt, A. R., Cooke, M., Kim, M. J., Melzer, T. R., Keenan, R., Ireland, D., Ramrakha, S., Poulton, R., Caspi, A., Moffitt, T. E. and Hariri, A. R. (2019) General functional connectivity: Shared features of resting-state and task fMRI drive reliable and heritable individual differences in functional brain networks. Neurolmage, 189, 516-532. URL: http: //www.sciencedirect.com/science/article/pii/s1053811919300746.

Elliott, M. L., Knodt, A. R., Ireland, D., Morris, M. L., Poulton, R., Ramrakha, S., Sison, M. L., Moffitt, T. E., Caspi, A. and Hariri, A. R. (2020) What Is the Test-Retest Reliability of Common Task-Functional MRI Measures? New Empirical Evidence and a Meta-Analysis. Psychological Science, 31, 792-806. URL: https ://doi .org/10.1177/0956797620916786. Publisher: SAGE Publications Inc.

Elman, I., Lowen, S., Frederick, B. B., Chi, W., Becerra, L. and Pitman, R. K. (2009) Functional Neuroimaging of Reward Circuitry Responsivity to Monetary Gains and Losses in Posttraumatic Stress Disorder. Biological Psychiatry, 66, 1083-1090. URL: http://www.sciencedirect.com/science/article/pii/s000632230900732X.

Ersche, K. D. (2020) Resilience to trauma: Just a matter of control? Science, 367, 734-735. URL: https : //science. sciencemag. org/content/367/6479/734. Publisher: American Association for the Advancement of Science Section: Perspective.

Falconer, E., Bryant, R., Felmingham, K. L., Kemp, A. H., Gordon, E., Peduto, A., Olivieri, G. and Williams, L. M. (2008) The neural networks of inhibitory control in posttraumatic stress disorder. Journal of Psychiatry \& Neuroscience : JPN, 33, 413-422. URL: https://www.ncbi.nlm.nih.gov/pmc/articles/PMC2527717/. 
Feder, A., Mota, N., Salim, R., Rodriguez, J., Singh, R., Schaffer, J., Schechter, C. B., Cancelmo, L. M., Bromet, E. J., Katz, C. L., Reissman, D. B., Ozbay, F., Kotov, R., Crane, M., Harrison, D. J., Herbert, R., Levin, S. M., Luft, B. J., Moline, J. M., Stellman, J. M., Udasin, I. G., Landrigan, P. J., Zvolensky, M. J., Yehuda, R., Southwick, S. M. and Pietrzak, R. H. (2016) Risk, coping and PTSD symptom trajectories in World Trade Center responders. Journal of Psychiatric Research, 82, 68-79. URL: http://www.sciencedirect.com/science/article/pii/S0022395616301327.

Feder, A., Nestler, E. J. and Charney, D. S. (2009) Psychobiology and molecular genetics of resilience. Nature Reviews Neuroscience, 10, 446-457. URL: https://www.nature.com/articles/nrn2649.

Felmingham, K. L., Falconer, E. M., Williams, L., Kemp, A. H., Allen, A., Peduto, A. and Bryant, R. A. (2014) Reduced Amygdala and Ventral Striatal Activity to Happy Faces in PTSD Is Associated with Emotional Numbing. PLOS ONE, 9, e103653. URL: https://journals.plos.org/plosone/article?id=10.1371/journal . pone. 0103653.

Finn, E. S., Glerean, E., Khojandi, A. Y., Nielson, D., Molfese, P. J., Handwerker, D. A. and Bandettini, P. A. (2020) Idiosynchrony: From shared responses to individual differences during naturalistic neuroimaging. Neurolmage, 215, 116828. URL: http: //www.sciencedirect.com/science/article/pii/s1053811920303153.

Fonzo, G. A., Goodkind, M. S., Oathes, D. J., Zaiko, Y. V., Harvey, M., Peng, K. K., Weiss, M. E., Thompson, A. L., Zack, S. E., Lindley, S. E., Arnow, B. A., Jo, B., Gross, J. J., Rothbaum, B. O. and Etkin, A. (2017) PTSD Psychotherapy Outcome Predicted by Brain Activation During Emotional Reactivity and Regulation. American Journal of Psychiatry, 174, 1163-1174. URL: https://ajp.psychiatryonline.org/doi/full/10.1176/appi.ajp.2017.16091072.

Fonzo, G. A., Simmons, A. N., Thorp, S. R., Norman, S. B., Paulus, M. P. and Stein, M. B. (2010) Exaggerated and Disconnected Insular-Amygdalar Blood Oxygenation Level-Dependent Response to Threat-Related Emotional Faces in Women with Intimate-Partner Violence Posttraumatic Stress Disorder. Biological Psychiatry, 68, 433-441. URL: http://www . sciencedirect.com/science/article/pii/s0006322310004221.

Fritz, J., Fried, E. I., Goodyer, I. M., Wilkinson, P. O. and van Harmelen, A.-L. (2018a) A Network Model of Resilience Factors for Adolescents with and without Exposure to Childhood Adversity. Scientific Reports, 8, 15774. URL: https ://www. nature . com/articles/s41598-018-34130-2.

Fritz, J., de Graaff, A. M., Caisley, H., van Harmelen, A.-L. and Wilkinson, P. O. (2018b) A Systematic Review of Amenable Resilience Factors That Moderate and/or Mediate the Relationship Between Childhood Adversity and Mental Health in Young People. Frontiers in Psychiatry, 9. URL: https ://www .frontiersin .org/articles/10.3389/fpsyt. 2018.00230/full? report=reader. Publisher: Frontiers.

Fritz, J., Stretton, J., Askelund, A. D., Schweizer, S., Walsh, N. D., Elzinga, B. M., Goodyer, I. M., Wilkinson, P. O. and van Harmelen, A.-L. (2019) Mood and neural responses to social rejection do not seem to be altered in resilient adolescents with a history of adversity. Development and Psychopathology, 1-13. URL: https://www. cambridge.org/core/journals/ development-and-psychopathology/article/mood-and-neural-responses-to-social-rejection-do-not-seem-to-bealtered-in-resilient-adolescents-with-a-history-of-adversity/DC3582A849EE821A81F3C8F5ACA6517B.

Fullana, M. A., Albajes-Eizagirre, A., Soriano-Mas, C., Vervliet, B., Cardoner, N., Benet, O., Radua, J. and Harrison, B. J. (2018) Fear extinction in the human brain: A meta-analysis of $\mathrm{fMRI}$ studies in healthy participants. Neuroscience \& Biobehavioral Reviews, 88, 16-25. URL: http://www.sciencedirect.com/science/article/pii/s0149763417309600.

Fullana, M. A., Dunsmoor, J. E., Schruers, K. R. J., Savage, H. S., Bach, D. R. and Harrison, B. J. (2020) Human fear conditioning: From neuroscience to the clinic. Behaviour Research and Therapy, 124, 103528. URL: http://www.sciencedirect.com/ science/article/pii/s0005796719302141.

Gee, D. G. (2020) Caregiving influences on emotional learning and regulation: applying a sensitive period model. Current Opinion in Behavioral Sciences, 36, 177-184. URL: https://www.sciencedirect.com/science/article/pii/ s2352154620301625. 
Getnet, B., Medhin, G. and Alem, A. (2019) Symptoms of post-traumatic stress disorder and depression among Eritrean refugees in Ethiopia: identifying direct, meditating and moderating predictors from path analysis. BMJ Open, 9, e021142. URL: https : //bmjopen.bmj .com/content/9/1/e021142. Publisher: British Medical Journal Publishing Group Section: Mental health.

Goodyer, I. M., Croudace, T., Dunn, V., Herbert, J. and Jones, P. B. (2010) Cohort Profile: Risk patterns and processes for psychopathology emerging during adolescence: the ROOTS project. International Journal of Epidemiology, 39, 361-369. URL: https://academic . oup.com/ije/article/39/2/361/678184.

Gould, F., Clarke, J., Heim, C., Harvey, P., Majer, M. and Nemeroff, C. (2012) The effects of child abuse and neglect on cognitive functioning in adulthood. Journal of Psychiatric Research, 46, 500-506.

Green, B. L. (1990) Defining Trauma: Terminology and Generic Stressor Dimensions. Journal of Applied Social Psychology, 20, 1632-1642. URL: https : //onlinelibrary.wiley.com/doi/abs/10.1111/j.1559-1816.1990.tb01498.x. _eprint: https://onlinelibrary.wiley.com/doi/pdf/10.1111/j.1559-1816.1990.tb01498.x.

Greenberg, M. T. (2006) Promoting Resilience in Children and Youth. Annals of the New York Academy of Sciences, 1094, 139150. URL: https://nyaspubs .onlinelibrary.wiley.com/doi/abs/10.1196/annals. 1376.013.

Hanson, J. L., Albert, D., Iselin, A.-M. R., Carré, J. M., Dodge, K. A. and Hariri, A. R. (2016) Cumulative stress in childhood is associated with blunted reward-related brain activity in adulthood. Social Cognitive and Affective Neuroscience, 11, 405412. URL: https://academic. oup.com/scan/article/11/3/405/2375092.

Hanson, J. L., Hariri, A. R. and Williamson, D. E. (2015) Blunted Ventral Striatum Development in Adolescence Reflects Emotional Neglect and Predicts Depressive Symptoms. Biological Psychiatry, 78, 598-605. URL: http: //www . sciencedirect . com/science/article/pii/s000632231500431X.

van Harmelen, A.-L., Gibson, J. L., Clair, M. C. S., Owens, M., Brodbeck, J., Dunn, V., Lewis, G., Croudace, T., Jones, P. B., Kievit, R. A. and Goodyer, I. M. (2016) Friendships and Family Support Reduce Subsequent Depressive Symptoms in At-Risk Adolescents. PLOS ONE, 11, e0153715. URL: https://journals.plos.org/plosone/article?id=10.1371/journal.pone. 0153715 .

van Harmelen, A.-L., Hauber, K., Moor, B. G., Spinhoven, P., Boon, A. E., Crone, E. A. and Elzinga, B. M. (2014) Childhood Emotional Maltreatment Severity Is Associated with Dorsal Medial Prefrontal Cortex Responsivity to Social Exclusion in Young Adults. PLOS ONE, 9, e85107. URL: https://journals.plos.org/plosone/article?id=10.1371/journal.pone. 0085107. Publisher: Public Library of Science.

van Harmelen, A. L., Kievit, R. A., loannidis, K., Neufeld, S., Jones, P. B., Bullmore, E., Dolan, R., Consortium, T. N., Fonagy, P. and Goodyer, I. (2017) Adolescent friendships predict later resilient functioning across psychosocial domains in a healthy community cohort. Psychological Medicine, 47, 2312-2322. URL: https://www.cambridge.org/ core/journals/psychological-medicine/article/adolescent-friendships-predict-later-resilient-functioningacross-psychosocial-domains-in-a-healthy-community-cohort/E8D06DC512C7A0EC720FF767F9E44504.

Harpur, L. J., Polek, E. and van Harmelen, A.-L. (2015) The role of timing of maltreatment and child intelligence in pathways to low symptoms of depression and anxiety in adolescence. Child Abuse \& Neglect, 47, 24-37. URL: http: //www.sciencedirect.com/science/article/pii/s0145213415002124.

Hofmann, S. G., Asmundson, G. J. G. and Beck, A. T. (2013) The Science of Cognitive Therapy. Behavior Therapy, 44, $199-212$. URL: http://www.sciencedirect.com/science/article/pii/s0005789411000591.

Holz, N. E., Tost, H. and Meyer-Lindenberg, A. (2020) Resilience and the brain: a key role for regulatory circuits linked to social stress and support. Molecular Psychiatry, 25, 379-396. URL: https://www.nature.com/articles/s41380-019-0551-9. Number: 2 Publisher: Nature Publishing Group.

Hoorelbeke, K., Van den Bergh, N., Wichers, M. and Koster, E. H. W. (2019) Between vulnerability and resilience: A network analysis of fluctuations in cognitive risk and protective factors following remission from depression. Behaviour Research and Therapy, 116, 1-9. URL: http://www.sciencedirect.com/science/article/pii/s0005796719300166. 
Horn, S. R., Pietrzak, R. H., Schechter, C., Bromet, E. J., Katz, C. L., Reissman, D. B., Kotov, R., Crane, M., Harrison, D. J., Herbert, R., Luft, B. J., Moline, J. M., Stellman, J. M., Udasin, I. G., Landrigan, P. J., Zvolensky, M. J., Southwick, S. M. and Feder, A. (2016) Latent typologies of posttraumatic stress disorder in World Trade Center responders. Journal of Psychiatric Research, 83, 151-159. URL: http://www.sciencedirect.com/science/article/pii/s0022395616302813.

ligaya, K., Hauser, T. U., Kurth-Nelson, Z., O’Doherty, J. P., Dayan, P. and Dolan, R. J. (2019) Hippocampal-midbrain circuit enhances the pleasure of anticipation in the prefrontal cortex. bioRxiv, 588699. URL: https://www . biorxiv. org/content/ $10.1101 / 588699 \mathrm{v} 1$.

loannidis, K., Askelund, A. D., Kievit, R. A. and van Harmelen, A.-L. (2020) The complex neurobiology of resilient functioning after childhood maltreatment. BMC Medicine, 18, 32. URL: https://doi .org/10.1186/s12916-020-1490-7.

Jacob, S. N., Dodge, C. P. and Vasterling, J. J. (2019) Posttraumatic stress disorder and neurocognition: A bidirectional relationship? Clinical Psychology Review, 72, 101747. URL: http://www.sciencedirect.com/science/article/pii/ S0272735818303775.

Kaldewaij, R., Koch, S. B. J., Hashemi, M. M., Zhang, W., Klumpers, F. and Roelofs, K. (2021) Anterior prefrontal brain activity during emotion control predicts resilience to post-traumatic stress symptoms. Nature Human Behaviour.

Kalisch, R., Baker, D. G., Basten, U., Boks, M. P., Bonanno, G. A., Brummelman, E., Chmitorz, A., Fernàndez, G., Fiebach, C. J., Galatzer-Levy, I., Geuze, E., Groppa, S., Helmreich, I., Hendler, T., Hermans, E. J., Jovanovic, T., Kubiak, T., Lieb, K., Lutz, B., Müller, M. B., Murray, R. J., Nievergelt, C. M., Reif, A., Roelofs, K., Rutten, B. P. F., Sander, D., Schick, A., Tüscher, O., Diest, I. V., Harmelen, A.-L. v., Veer, I. M., Vermetten, E., Vinkers, C. H., Wager, T. D., Walter, H., Wessa, M., Wibral, M. and Kleim, B. (2017) The resilience framework as a strategy to combat stress-related disorders. Nature Human Behaviour, 1 , 784. URL: https://www.nature.com/articles/s41562-017-0200-8.

Kalisch, R., Cramer, A. O. J., Binder, H., Fritz, J., Leertouwer, I., Lunansky, G., Meyer, B., Timmer, J., Veer, I. M. and van Harmelen, A.-L. (2019) Deconstructing and Reconstructing Resilience: A Dynamic Network Approach. Perspectives on Psychological Science, 14, 765-777. URL: https : //doi .org/10.1177/1745691619855637. Publisher: SAGE Publications Inc.

Karam, E. G., Friedman, M. J., Hill, E. D., Kessler, R. C., McLaughlin, K. A., Petukhova, M., Sampson, L., Shahly, V., Angermeyer, M. C., Bromet, E. J., Girolamo, G. d., Graaf, R. d., Demyttenaere, K., Ferry, F., Florescu, S. E., Haro, J. M., He, Y., Karam, A. N., Kawakami, N., Kovess-Masfety, V., Medina-Mora, M. E., Browne, M. A. O., Posada-Villa, J. A., Shalev, A. Y., Stein, D. J., Viana, M. C., Zarkov, Z. and Koenen, K. C. (2014) Cumulative Traumas and Risk Thresholds: 12-Month PTSD in the World Mental Health (WMH) Surveys. Depression and Anxiety, 31, 130-142. URL: https://onlinelibrary.wiley.com/ doi/abs/10.1002/da.22169.

Keane, T. M., Fairbank, J. A., Caddell, J. M., Zimering, R. T., Taylor, K. L. and Mora, C. A. (1989) Clinical evaluation of a measure to assess combat exposure. Psychological Assessment: A Journal of Consulting and Clinical Psychology, 1, 53-55.

Keynan, J. N., Cohen, A., Jackont, G., Green, N., Goldway, N., Davidov, A., Meir-Hasson, Y., Raz, G., Intrator, N., Fruchter, E., Ginat, K., Laska, E., Cavazza, M. and Hendler, T. (2019) Electrical fingerprint of the amygdala guides neurofeedback training for stress resilience. Nature Human Behaviour, 3, 63. URL: https : / www .nature .com/articles/s41562-018-0484-3.

Lepore, S. J. and Kliewer, W. (2019) Social Intelligence Attenuates Association between Peer Victimization and Depressive Symptoms among Adolescents. Psychology of Violence, 9, 644-652.

Liebenberg, L. (2020) Reconsidering interactive resilience processes in mental health: Implications for child and youth services. Journal of Community Psychology, 48, 1365-1380. URL: https://onlinelibrary.wiley.com/doi/abs/10.1002/ jcop.22331. _eprint: https://onlinelibrary.wiley.com/doi/pdf/10.1002/jcop.22331.

Lissek, S. and van Meurs, B. (2015) Learning models of PTSD: Theoretical accounts and psychobiological evidence. International Journal of Psychophysiology, 98, 594-605. URL: http://www.sciencedirect.com/science/article/pii/ s016787601401647x. 
Luthar, S. S., Sawyer, J. A. and Brown, P. J. (2006) Conceptual Issues in Studies of Resilience. Annals of the New York Academy of Sciences, 1094, 105-115. URL: https: //nyaspubs . onlinelibrary .wiley.com/doi/abs/10.1196/annals.1376.009.

Maier, S. F. and Watkins, L. R. (2010) Role of the medial prefrontal cortex in coping and resilience. Brain Research, 1355, 52-60. URL: http://www.sciencedirect.com/science/article/pii/s0006899310018214.

Mary, A., Dayan, J., Leone, G., Postel, C., Fraisse, F., Malle, C., Vallée, T., Klein-Peschanski, C., Viader, F., Sayette, V. d. I., Peschanski, D., Eustache, F. and Gagnepain, P. (2020) Resilience after trauma: The role of memory suppression. Science, 367. URL: https://science.sciencemag.org/content/367/6479/eaay8477. Publisher: American Association for the Advancement of Science Section: Research Article.

McGloin, J. M. and Widom, C. S. (2001) Resilience among abused and neglected children grown up. Development and Psychopathology, 13, 1021-1038.

McLean, C. P. and Anderson, E. R. (2009) Brave men and timid women? A review of the gender differences in fear and anxiety. Clinical Psychology Review, 29, 496-505. URL: https://www.sciencedirect.com/science/article/pii/ s0272735809000671.

Meili, I. and Maercker, A. (2019) Cultural perspectives on positive responses to extreme adversity: A playing field for metaphors. Transcultural Psychiatry, 56, 1056-1075. URL: https ://doi .org/10.1177/1363461519844355.

Mendenhall, E. and Kim, A. W. (2019) How to Fail a Scale: Reflections on a Failed Attempt to Assess Resilience. Culture, Medicine, and Psychiatry, 43, 315-325. URL: https ://doi .org/10.1007/s11013-018-9617-4.

Milad, M. R., Wright, C. I., Orr, S. P., Pitman, R. K., Quirk, G. J. and Rauch, S. L. (2007) Recall of Fear Extinction in Humans Activates the Ventromedial Prefrontal Cortex and Hippocampus in Concert. Biological Psychiatry, 62, 446-454. URL: http://www.sciencedirect.com/science/article/pii/S0006322306012984.

Moreno-López, L., loannidis, K., Askelund, A. D., Smith, A. J., Schueler, K. and van Harmelen, A.-L. (2020) The Resilient Emotional Brain: A Scoping Review of the Medial Prefrontal Cortex and Limbic Structure and Function in Resilient Adults With a History of Childhood Maltreatment. Biological Psychiatry: Cognitive Neuroscience and Neuroimaging, 5, 392-402. URL: http://www.sciencedirect.com/science/article/pii/S2451902219303489.

Méndez Leal, A. S. and Silvers, J. A. (2021) Neurobiological Markers of Resilience to Early-Life Adversity During Adolescence. Biological Psychiatry: Cognitive Neuroscience and Neuroimaging, 6, 238-247. URL: https://www.sciencedirect. com/science/article/pii/s2451902220302391.

Nawijn, L., van Zuiden, M., Frijling, J. L., Koch, S. B. J., Veltman, D. J. and Olff, M. (2015) Reward functioning in PTSD: A systematic review exploring the mechanisms underlying anhedonia. Neuroscience \& Biobehavioral Reviews, 51, 189-204. URL: http://www.sciencedirect.com/science/article/pii/s0149763415000305.

Nord, C. L., Gray, A., Charpentier, C. J., Robinson, O. J. and Roiser, J. P. (2017) Unreliability of putative fMRI biomarkers during emotional face processing. Neurolmage, 156, 119-127. URL: http://www.sciencedirect.com/science/article/ pii/s1053811917304160.

Patel, R., Spreng, R. N., Shin, L. M. and Girard, T. A. (2012) Neurocircuitry models of posttraumatic stress disorder and beyond: A meta-analysis of functional neuroimaging studies. Neuroscience \& Biobehavioral Reviews, 36, 2130-2142. URL: https: //www.sciencedirect.com/science/article/pii/s0149763412000930.

Phelps, E. A., Delgado, M. R., Nearing, K. I. and LeDoux, J. E. (2004) Extinction Learning in Humans: Role of the Amygdala and vmPFC. Neuron, 43, 897-905. URL: http://www.sciencedirect.com/science/article/pii/s0896627304005689.

Pietrzak, R. H., Feder, A., Singh, R., Schechter, C. B., Bromet, E. J., Katz, C. L., Reissman, D. B., Ozbay, F., Sharma, V., Crane, M., Harrison, D., Herbert, R., Levin, S. M., Luft, B. J., Moline, J. M., Stellman, J. M., Udasin, I. G., Landrigan, P. J. and Southwick, S. M. (2014a) Trajectories of PTSD risk and resilience in World Trade Center responders: an 8-year prospective cohort study. Psychological Medicine, 44, 205-219. URL: https://www. cambridge.org/core/journals/psychologicalmedicine/article/trajectories-of-ptsd-risk-and-resilience-in-world-trade-center-responders-an-8yearprospective-cohort-study/64F888AFBC86EDE3F29657ABE45910A3. 
Pietrzak, R. H., el Gabalawy, R., Tsai, J., Sareen, J., Neumeister, A. and Southwick, S. M. (2014b) Typologies of posttraumatic stress disorder in the U.S. adult population. Journal of Affective Disorders, 162, 102-106. URL: http: //www . sciencedirect . com/science/article/pii/s0165032714001359.

Pitman, R. K., Rasmusson, A. M., Koenen, K. C., Shin, L. M., Orr, S. P., Gilbertson, M. W., Milad, M. R. and Liberzon, I. (2012) Biological studies of post-traumatic stress disorder. Nature Reviews Neuroscience, 13, 769-787. URL: https : //www . nature . com/articles/nrn3339.

Portnoy, G. A., Relyea, M. R., Decker, S., Shamaskin-Garroway, A., Driscoll, M., Brandt, C. A. and Haskell, S. G. (2018) Understanding Gender Differences in Resilience Among Veterans: Trauma History and Social Ecology. Journal of Traumatic Stress, 31, 845-855. WOS:000453529100006.

Powers, M. B., Warren, A. M., Rosenfield, D., Roden-Foreman, K., Bennett, M., Reynolds, M. C., Davis, M. L., Foreman, M. L., Petrey, L. B. and Smits, J. A. J. (2014) Predictors of PTSD symptoms in adults admitted to a Level I trauma center: A prospective analysis. Journal of Anxiety Disorders, 28, 301-309. URL: http://www. sciencedirect.com/science/article/

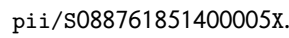

Reddan, M. C., Wager, T. D. and Schiller, D. (2018) Attenuating Neural Threat Expression with Imagination. Neuron, 100, 994-1005.e4. URL: http://www.sciencedirect.com/science/article/pii/s0896627318309553.

Rodman, A. M., Jenness, J. L., Weissman, D. G., Pine, D. S. and McLaughlin, K. A. (2019) Neurobiological Markers of Resilience to Depression Following Childhood Maltreatment: The Role of Neural Circuits Supporting the Cognitive Control of Emotion. Biological Psychiatry, 86, 464-473. URL: https://www.biologicalpsychiatryjournal.com/article/s00063223(19)31333-2/abstract. Publisher: Elsevier.

van Rooij, S. J. H., Stevens, J. S., Ely, T. D., Hinrichs, R., Michopoulos, V., Winters, S. J., Ogbonmwan, Y. E., Shin, J., Nugent, N. R., Hudak, L. A., Rothbaum, B. O., Ressler, K. J. and Jovanovic, T. (2018) The Role of the Hippocampus in Predicting Future Posttraumatic Stress Disorder Symptoms in Recently Traumatized Civilians. Biological Psychiatry, 84, 106-115. URL: http://www.sciencedirect.com/science/article/pii/s0006322317319893.

Rutter, M. (2012) Resilience as a dynamic concept. Development and Psychopathology, 24, 335-344. URL: https ://www . cambridge .org/core/journals/development-and-psychopathology/article/resilience-as-a-dynamicconcept/B82378BCEFAA45A6D5BB433989312F55.

Sailer, U., Robinson, S., Fischmeister, F. P. S., König, D., Oppenauer, C., Lueger-Schuster, B., Moser, E., Kryspin-Exner, I. and Bauer, H. (2008) Altered reward processing in the nucleus accumbens and mesial prefrontal cortex of patients with posttraumatic stress disorder. Neuropsychologia, 46, 2836-2844. URL: http://www.sciencedirect.com/science/article/ $\mathrm{pii/s0028393208002510.}$

Scheffer, M., Bolhuis, J. E., Borsboom, D., Buchman, T. G., Gijzel, S. M. W., Goulson, D., Kammenga, J. E., Kemp, B., Leemput, I. A. v. d., Levin, S., Martin, C. M., Melis, R. J. F., Nes, E. H. v., Romero, L. M. and Rikkert, M. G. M. O. (2018) Quantifying resilience of humans and other animals. Proceedings of the National Academy of Sciences, 115, 11883-11890. URL: https : //www. pnas.org/content/115/47/11883.

Schiller, D. and Delgado, M. R. (2010) Overlapping neural systems mediating extinction, reversal and regulation of fear. Trends in Cognitive Sciences, 14, 268-276. URL: http: //www. sciencedirect.com/science/article/pii/s1364661310000744.

Schultze-Lutter, F., Schimmelmann, B. G. and Schmidt, S. J. (2016) Resilience, risk, mental health and well-being: associations and conceptual differences. European Child \& Adolescent Psychiatry, 25, 459-466. URL: https : //doi .org/10. 1007/s00787016-0851-4.

Schweizer, S., Walsh, N. D., Stretton, J., Dunn, V. J., Goodyer, I. M. and Dalgleish, T. (2016) Enhanced emotion regulation capacity and its neural substrates in those exposed to moderate childhood adversity. Social Cognitive and Affective Neuroscience, 11, 272-281. URL: https://academic .oup.com/scan/article/11/2/272/2375091. Publisher: Oxford Academic. 
Scott, J. C., Matt, G. E., Wrocklage, K. M., Crnich, C., Jordan, J., Southwick, S. M., Krystal, J. H. and Schweinsburg, B. C. (2015) A quantitative meta-analysis of neurocognitive functioning in posttraumatic stress disorder. Psychological Bulletin, 141, $105-140$.

Scult, M. A., Knodt, A. R., Radtke, S. R., Brigidi, B. D. and Hariri, A. R. (2019) Prefrontal Executive Control Rescues Risk for Anxiety Associated with High Threat and Low Reward Brain Function. Cerebral Cortex, 29, 70-76. URL: https: //academic . oup.com/cercor/article/29/1/70/4637600.

Shalev, A., Liberzon, I. and Marmar, C. (2017) Post-Traumatic Stress Disorder. New England Journal of Medicine, 376, 24592469. URL: https://doi.org/10.1056/NEJMra1612499.

Silveira, S., Shah, R., Nooner, K. B., Nagel, B. J., Tapert, S. F., de Bellis, M. D. and Mishra, J. (2020) Impact of Childhood Trauma on Executive Function in Adolescence-Mediating Functional Brain Networks and Prediction of High-Risk Drinking. Biological Psychiatry: Cognitive Neuroscience and Neuroimaging, 5, 499-509. URL: http://www. sciencedirect. com/science/ article/pii/s2451902220300318.

Silvers, J. A., Lumian, D. S., Gabard-Durnam, L., Gee, D. G., Goff, B., Fareri, D. S., Caldera, C., Flannery, J., Telzer, E. H., Humphreys, K. L. and Tottenham, N. (2016) Previous Institutionalization Is Followed by Broader Amygdala-HippocampalPFC Network Connectivity during Aversive Learning in Human Development. Journal of Neuroscience, 36, 6420-6430. Place: Washington Publisher: Soc Neuroscience WOS:000379015300007.

Sinha, R., Lacadie, C. M., Constable, R. T. and Seo, D. (2016) Dynamic neural activity during stress signals resilient coping. Proceedings of the National Academy of Sciences, 113, 8837-8842. URL: https://www . pnas . org/content/113/31/8837.

Speer, M. E. and Delgado, M. R. (2017) Reminiscing about positive memories buffers acute stress responses. Nature Human Behaviour, 1, 0093. URL: https://www. nature.com/articles/s41562-017-0093.

Stevens, J. S. and Jovanovic, T. (2019) Role of social cognition in post-traumatic stress disorder: A review and meta-analysis. Genes, Brain and Behavior, 18, e12518. URL: https://onlinelibrary.wiley.com/doi/abs/10.1111/gbb.12518.

Stevens, J. S., Kim, Y. J., Galatzer-Levy, I. R., Reddy, R., Ely, T. D., Nemeroff, C. B., Hudak, L. A., Jovanovic, T., Rothbaum, B. O. and Ressler, K. J. (2017) Amygdala Reactivity and Anterior Cingulate Habituation Predict Posttraumatic Stress Disorder Symptom Maintenance After Acute Civilian Trauma. Biological Psychiatry, 81, 1023-1029. URL: http: //www.sciencedirect.com/science/article/pii/s0006322316331250.

Stratta, P., Capanna, C., Dell'Osso, L., Carmassi, C., Patriarca, S., Di Emidio, G., Riccardi, I., Collazzoni, A. and Rossi, A. (2015) Resilience and coping in trauma spectrum symptoms prediction: A structural equation modeling approach. Personality and Individual Differences, 77, 55-61. URL: http://www. sciencedirect.com/science/article/pii/s0191886914007636.

Street, A. E. and Dardis, C. M. (2018) Using a social construction of gender lens to understand gender differences in posttraumatic stress disorder. Clinical Psychology Review, 66, 97-105. Place: Oxford Publisher: Pergamon-Elsevier Science Ltd WOS:000452939800009.

Szucs, D. and loannidis, J. P. (2020) Sample size evolution in neuroimaging research: An evaluation of highly-cited studies (1990-2012) and of latest practices (2017-2018) in high-impact journals. Neurolmage, 221, 117164. URL: http://www . sciencedirect.com/science/article/pii/s1053811920306509.

Tashjian, S. M. and Galván, A. (2018) The Role of Mesolimbic Circuitry in Buffering Election-Related Distress. Journal of Neuroscience, 38, 2887-2898. URL: http://www. jneurosci.org/content/38/11/2887.

Thompson, N. J., Fiorillo, D., Rothbaum, B. O., Ressler, K. J. and Michopoulos, V. (2018) Coping strategies as mediators in relation to resilience and posttraumatic stress disorder. Journal of Affective Disorders, 225, 153-159. URL: http://www . sciencedirect.com/science/article/pii/s016503271632417X.

Tolin, D. F. and Foa, E. B. (2008) Sex differences in trauma and posttraumatic stress disorder: A quantitative review of 25 years of research. Psychological Trauma: Theory, Research, Practice, and Policy, S, 37-85. 
Walsh, W. A., Dawson, J. and Mattingly, M. J. (2010) How Are We Measuring Resilience Following Childhood Maltreatment? Is the Research Adequate and Consistent? What is the Impact on Research, Practice, and Policy? Trauma, Violence, \& Abuse, 11, 27-41. URL: https://doi.org/10.1177/1524838009358892.

Wang, L., Paul, N., Stanton, S. J., Greeson, J. M. and Smoski, M. (2013) Loss of Sustained Activity in the Ventromedial Prefrontal Cortex in Response to Repeated Stress in Individuals with Early-Life Emotional Abuse: Implications for Depression Vulnerability. Frontiers in Psychology, 4. URL: https://www .frontiersin.org/articles/10.3389/fpsyg. 2013.00320/full\#B46.

Watson, P. (2019) PTSD as a Public Mental Health Priority. Current Psychiatry Reports, 21, 61. URL: https://doi.org/10. 1007/s11920-019-1032-1.

Waugh, C. E. and Koster, E. H. W. (2015) A resilience framework for promoting stable remission from depression. Clinical Psychology Review, 41, 49-60. URL: http://www.sciencedirect.com/science/article/pii/s0272735814000737.

Weathers, F., Blake, D., Schnurr, P., Kaloupek, D., Marx, B. and Keane, T. (2013) Clinician-Administered PTSD Scale for DSM-5 (CAPS-5). URL: https://www.ptsd.va.gov/professional/assessment/adult-int/caps . asp.

van der Werff, S. J. A., van den Berg, S. M., Pannekoek, J. N., Elzinga, B. M. and Van Der Wee, N. J. A. (2013) Neuroimaging resilience to stress: a review. Frontiers in Behavioral Neuroscience, 7. URL: https://www.frontiersin.org/articles/10. 3389/fnbeh.2013.00039/full.

Whittle, S., Dennison, M., Vijayakumar, N., Simmons, J. G., Yücel, M., Lubman, D. I., Pantelis, C. and Allen, N. B. (2013) Childhood Maltreatment and Psychopathology Affect Brain Development During Adolescence. Journal of the American Academy of Child \& Adolescent Psychiatry, 52, 940-952.e1. URL: http://www.sciencedirect.com/science/article/pii/ S089085671300405X.

Williams, M., Metzger, I., Leins, C. and DeLapp, C. (2018) Assessing Racial Trauma Within a DSM-5 Framework: The UConn Racial/Ethnic Stress \& Trauma Survey. Practice Innovations, 3, 242-260. URL: insights . ovid .com.

World Health Organization (1993) The ICD-10 Classification of Mental and Behavioural Disorders: Diagnostic Criteria for Research. World Health Organization. Google-Books-ID: cnUODgAAQBAJ.

Wymbs, N. F., Orr, C., Albaugh, M. D., Althoff, R. R., O'Loughlin, K., Holbrook, H., Garavan, H., Montalvo-Ortiz, J. L., Mostofsky, S., Hudziak, J. and Kaufman, J. (2020) Social supports moderate the effects of child adversity on neural correlates of threat processing. Child Abuse \& Neglect, 102, 104413. URL: http://www.sciencedirect.com/science/article/pii/ S0145213420300685.

Yehuda, R. and Flory, J. D. (2007) Differentiating biological correlates of risk, PTSD, and resilience following trauma exposure. Journal of Traumatic Stress, 20, 435-447. URL: https : //onlinelibrary . wiley . com/doi/abs/10. 1002/jts .20260.

Yehuda, R., Hoge, C. W., McFarlane, A. C., Vermetten, E., Lanius, R. A., Nievergelt, C. M., Hobfoll, S. E., Koenen, K. C., Neylan, T. C. and Hyman, S. E. (2015) Post-traumatic stress disorder. Nature Reviews Disease Primers, 1, 15057. URL: https: //www.nature.com/articles/nrdp201557.

Yule, K., Houston, J. and Grych, J. (2019) Resilience in Children Exposed to Violence: A Meta-analysis of Protective Factors Across Ecological Contexts. Clinical Child and Family Psychology Review, 22, 406-431. URL: https://doi.org/10.1007/ s10567-019-00293-1.

Zilverstand, A., Parvaz, M. A. and Goldstein, R. Z. (2017) Neuroimaging cognitive reappraisal in clinical populations to define neural targets for enhancing emotion regulation. A systematic review. Neurolmage, 151, 105-116. URL: http://www. sciencedirect.com/science/article/pii/s1053811916302270.

Zotev, V., Phillips, R., Misaki, M., Wong, C. K., Wurfel, B. E., Krueger, F., Feldner, M. and Bodurka, J. (2018) Real-time fMRI neurofeedback training of the amygdala activity with simultaneous EEG in veterans with combat-related PTSD. Neurolmage: Clinical, 19, 106-121. URL: https://www.sciencedirect.com/science/article/pii/s2213158218301190. 